\title{
Outbreak of bacterial phlebitis related to peripheral intravenous catheters at a general hospital in Brazil
}

\author{
B Quental ${ }^{1}$, R Saad $^{1 *}$, L Duarte $^{1}$, J Oliveira ${ }^{1}$, A Frazilio ${ }^{2}$ \\ From 3rd International Conference on Prevention and Infection Control (ICPIC 2015) \\ Geneva, Switzerland. 16-19 June 2015
}

\section{Introduction}

Device related infections are prevalent all over the world. Peripheral intravenous catheters are the most used intravascular devices and the less associated with infections.

\section{Objectives}

To describe the investigation and control measures of an outbreak of bacterial phlebitis at a general hospital in São Paulo, Brazil.

\section{Methods}

Bacterial phlebitis was defined according to the Centers for Disease Control criteria. Each patient's data were collected from their medical files. After tabulation of the data, we could find common factors and propose control measures.

\section{Results}

From January to June, 2013, 11 cases of bacterial phlebitis related to peripheral Intravenous catheters were reported. We could not find only one factor associated. Most of the cases occurred after 2 days of the punction (42\%), and $72 \%$ of them were performed at the emergency department. We noticed that $37 \%$ of these catheters were manipulated in the ICU and $48 \%$ of the punctures were localized at the antecubital fossa. Of these cases, only one patient cursed with bloodstream infection, and this was due to Staphylococcus aureus methicillin sensible. We performed observational auditing of insertion and manipulation of these catheters, and we could notice that the most frequent process problems were hand hygiene and hub disinfection. There was no change in the kind of material used in the hospital. Based on these findings, we proposed several measures for infection control, including a hand hygiene campaign, discussion of every case with the multiprofessional team, a global training of $100 \%$ of the health care team regarding punction and manipulation of the catheters, reinforcement of daily evaluation of the need of maintaining the catheter and priorization of more distal punction. The outbreak was controlled in august, 2013.

\section{Conclusion}

Active infection control programs, including infection surveillance and implementation of prevention measures are important for all types of intravascular devices, including peripheral Intravenous catheters, in order to improve patient safety.

\section{Disclosure of interest}

None declared.

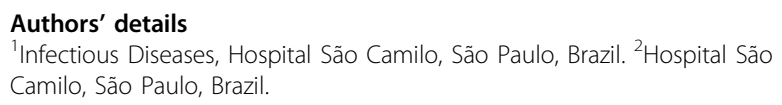

Published: 16 June 2015

doi:10.1186/2047-2994-4-S1-P215

Cite this article as: Quental et al: Outbreak of bacterial phlebitis related to peripheral intravenous catheters at a general hospital in Brazil. Antimicrobial Resistance and Infection Control 2015 4(Suppl 1):P215. 